\title{
Article \\ Cembranoids from Octocoral Lobophytum crassum (von Marenzeller, 1886)
}

\author{
Yao-Tsung Yeh ${ }^{1,2,+}$, Sung-Chun Lin ${ }^{3,+}$, Gene-Hsiang Lee ${ }^{4}$, Zhi-Hong Wen ${ }^{5,6} \mathbb{C}^{\mathbb{D}}$, Tsong-Long Hwang $7,8,9,10 \mathbb{D}$, \\ Yu-Jen Wu ${ }^{11}$, Jih-Jung Chen ${ }^{12}$, Lee-Shing Fang 5,13,14, Mei-Kang Yuan 15,16,* and Ping-Jyun Sung 1,2,5,17,18,*1D
}

check for

updates

Citation: Yeh, Y.-T.; Lin, S.-C.; Lee, G.-H.; Wen, Z.-H.; Hwang, T.-L.; Wu, Y.-J.; Chen, J.-J.; Fang, L.-S.; Yuan, M.-K.; Sung, P.-J. Cembranoids from Octocoral Lobophytum crassum (von Marenzeller, 1886). Mar. Drugs 2021, 19, 130. https://doi.org/ $10.3390 / \mathrm{md} 19030130$

Academic Editor: Hitoshi Sashiwa

Received: 8 February 2021

Accepted: 24 February 2021

Published: 27 February 2021

Publisher's Note: MDPI stays neutral with regard to jurisdictional claims in published maps and institutional affiliations.

Copyright: (c) 2021 by the authors. Licensee MDPI, Basel, Switzerland. This article is an open access article distributed under the terms and conditions of the Creative Commons Attribution (CC BY) license (https:/ / creativecommons.org/licenses/by/ $4.0 /)$.
1 Graduate Institute of Marine Biology, National Dong Hwa University, Pingtung 944401, Taiwan; 610963011@gms.ndhu.edu.tw

2 National Museum of Marine Biology and Aquarium, Pingtung 944401, Taiwan

3 Department of Orthopaedic Surgery, Ping-Tung Christian Hospital, Pingtung 900026, Taiwan; 2572@ptch.org.tw

4 Instrumentation Center, National Taiwan University, Taipei 106319, Taiwan; ghlee@ntu.edu.tw

5 Department of Marine Biotechnology and Resources, National Sun Yat-sen University, Kaohsiung 804201, Taiwan; wzh@mail.nsysu.edu.tw (Z.-H.W.); lsfang@gcloud.csu.edu.tw (L.-S.F.)

6 Institute of BioPharmaceutical Sciences, National Sun Yat-sen University, Kaohsiung 804201, Taiwan

7 Graduate Institute of Natural Products, College of Medicine, Chang Gung University, Taoyuan 333323, Taiwan; ht1@mail.cgu.edu.tw

8 Research Center for Chinese Herbal Medicine, Graduate Institute of Healthy Industry Technology, College of Human Ecology, Chang Gung University of Science and Technology, Taoyuan 333324, Taiwan

9 Department of Anaesthesiology, Chang Gung Memorial Hospital, Taoyuan 333423, Taiwan

10 Department of Chemical Engineering, Ming Chi University of Technology, New Taipei City 243303, Taiwan

11 Department of Food Science and Nutrition, Meiho University, Pingtung 912009, Taiwan; x00002180@meiho.edu.tw

12 Faculty of Pharmacy, School of Pharmaceutical Sciences, National Yang Ming Chiao Tung University, Taipei 112304, Taiwan; jjungchen@nycu.edu.tw

13 Center for Environmental Toxin and Emerging-Contaminant Research, Cheng Shiu University, Kaohsiung 833301, Taiwan

14 Super Micro Mass Research and Technology Center, Cheng Shiu University, Kaohsiung 833301, Taiwan

15 Department of Medical Imaging and Radiology, Shu-Zen Junior College of Medicine and Management, Kaohsiung 821004, Taiwan

16 Department of Radiology, An Nan Hospital, China Medical University, Tainan 709204, Taiwan

17 Chinese Medicine Research and Development Center, China Medical University Hospital, Taichung 404394, Taiwan

18 Graduate Institute of Natural Products, Kaohsiung Medical University, Kaohsiung 807378, Taiwan

* Correspondence: D73905@mail.tmanh.org.tw (M.-K.Y.); pjsung@nmmba.gov.tw (P.-J.S.); Tel.: +886-8-882-5037 (P.-J.S.); Fax: +886-8-882-5087 (P.-J.S.)

+ The authors contributed equally to this work.

Abstract: Two cembranoids, including a new compound, lobocrassin I (1), as well as a known analogue, lobohedleolide (2), were obtained by solvent extraction from octocoral Lobophytum crassum. This study employed a spectroscopic approach to establish the structures of these two cembranoids, and utilized single-crystal X-ray diffraction analysis to determine their absolute configurations. The results of biological activity assays demonstrated that cembranoid 2 exhibited bioactivity against the protein expressions of inducible nitric oxide synthase (iNOS) lipopolysaccharide (LPS)-treated RAW 264.7 mouse macrophage cells.

Keywords: Lobophytum crassum; cembranoid; lobocrassin; lobohedleolide; X-ray; anti-inflammation; iNOS

\section{Introduction}

Cembrane-type diterpenoids are a group of 14-membered macrolides obtained from terrestrial and marine organisms, with novel structures and extensive bioactivities [1]. Octocorals belonging to the genera Lobophytum, Sarcophyton, and Sinularia are currently known to be critical sources for the supply of cembranoids [2]. In connection with our 
continuing studies of marine invertebrates with biomedical potential, we have focused considerable attention on invertebrates found in the marine habitat of the waters around Taiwan, with the aim of informing new drug development. In this research, we completed the preparation, structural identification, and anti-inflammatory activity assessment of a new cembranoid, lobocrassin I (1), as well as a known cembranoid, lobohedleolide (2) [3-6] (Figure 1), obtained from L. crassum (von Marenzeller, 1886) [7,8]. Lobophytum crassum is a rich cembranoid-containing octocoral distributed extensively in tropical Indo-Pacific Ocean, including Taiwanese waters where the Kuroshio current and South China Sea surface current converge to provide high biodiversity and the cembrane-type diterpenoids prepared from soft coral L. crassum were proven to have the potential to be used as therapeutic agents to treat inflammation [9-15]. This paper reported details of the isolation, structure determination, and biological evaluation of cembranoids $\mathbf{1}$ (lobocrassin I) and $\mathbf{2}$ (lobohedleolide) (Figure 1).

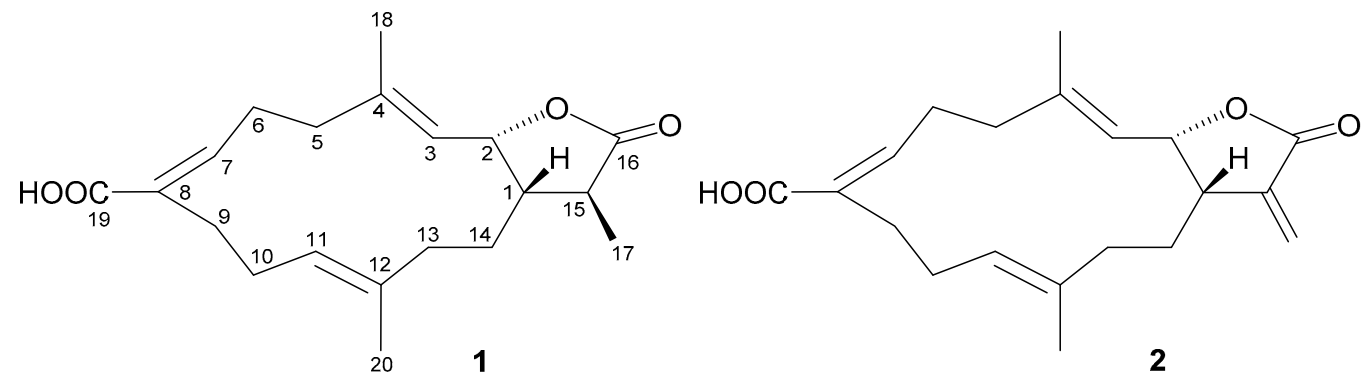

Figure 1. Structures of lobocrassin I (1) and lobohedleolide (2).

\section{Results and Discussion}

Freshly-collected L. crassum was frozen and subsequently freeze-dried, powdered, and extracted with a solvent mixture of methanol/dichloromethane $\left(\mathrm{MeOH} / \mathrm{CH}_{2} \mathrm{Cl}_{2}\right)$ at a 1:1 ratio to give an extract that was subsequently separated by organic solvent ethyl acetate (EtOAc)-water partitioning. The EtOAc layer was collected and loaded onto a column chromatograph with silica gel, and subsequently separated using high performance liquid chromatography (HPLC), yielding cembranoids $\mathbf{1}$ and 2. The known compound was elucidated as lobohedleolide (2) by analysis of its spectroscopic data and comparison with previously reported values [3].

Lobocrassin I (1) was obtained as colorless prisms. The positive mode high resolution electrospray ionization mass spectrum ((+)-HRESIMS) showed a peak at $m / z 355.18815$, suggesting the molecular formula $\mathrm{C}_{20} \mathrm{H}_{28} \mathrm{O}_{4}$ (calcd. for $\mathrm{C}_{20} \mathrm{H}_{28} \mathrm{O}_{4}+\mathrm{Na}$, 355.18798), indicating seven degrees of unsaturation in the compound. The IR spectrum revealed absorptions for $\alpha, \beta$-unsaturated carboxyl $\left(\nu_{\max } 3749 \sim 2216\right.$ and $\left.1710 \mathrm{~cm}^{-1}\right)$ and $\gamma$ - lactone $\left(\nu_{\max } 1766 \mathrm{~cm}^{-1}\right)$ groups. The ${ }^{13} \mathrm{C}$ NMR spectrum of $\mathbf{1}$ (Table 1 ) showed signals of 20 carbons. The multiplicities of carbon signals were determined from a distortionless enhancement by polarization transfer (DEPT)/heteronuclear single quantum coherence (HSQC) spectrum, indicating three methyls, six sp ${ }^{3}$ methylenes, three $\mathrm{sp}^{3}$ methines (one bearing a heteroatom), three $\mathrm{sp}^{2}$ methines, and five $\mathrm{sp}^{2}$ non-protonated carbons (two carbonyls and three olefins). From the ${ }^{1} \mathrm{H}$ and ${ }^{13} \mathrm{C}$ NMR spectra (Table 1$), 1$ was found to possess a $\gamma$-lactone $\left(\delta_{\mathrm{C}} 179.3, \mathrm{C}-16\right)$, a carboxyl carbon $\left(\delta_{\mathrm{C}} 170.7, \mathrm{C}-19\right)$, and three tri- substituted olefins $\left(\delta_{\mathrm{H}} 5.74,1 \mathrm{H}, \mathrm{dd}, J=8.4\right.$, $3.6 \mathrm{~Hz}, \mathrm{H}-7 ; 5.21,1 \mathrm{H}, \mathrm{d}, J=10.8 \mathrm{~Hz}, \mathrm{H}-3 ; 4.93,1 \mathrm{H}, \mathrm{dd}, J=8.8,7.6 \mathrm{~Hz}, \mathrm{H}-11 ; \delta_{\mathrm{C}} 119.6$, CH-3; 142.4, C-4; 147.8, CH-7; 128.7, C-8; 122.7, CH-11; 135.5, C-12). Five double bonds that accounted for the five degrees of unsaturation were identified. The remaining two degrees of unsaturation delineated the configuration, and indicated that $\mathbf{1}$ was a bicyclic molecule. 
Table 1. ${ }^{1} \mathrm{H}$ and ${ }^{13} \mathrm{C}$ NMR data for cembranoids $\mathbf{1}$ and 2.

\begin{tabular}{|c|c|c|c|c|}
\hline \multirow[b]{2}{*}{ Position } & \multicolumn{2}{|c|}{1} & \multicolumn{2}{|l|}{2} \\
\hline & $\delta_{\mathrm{H}}{ }^{\mathrm{a}}(J$ in $\mathrm{Hz})$ & $\delta_{C}^{b}$ & $\delta_{H}{ }^{a}(J$ in $\mathrm{Hz})$ & $\delta_{C}{ }^{b}$ \\
\hline 1 & $2.21 \mathrm{~m}$ & $46.6, \mathrm{CH}^{\mathrm{c}}$ & $3.11 \mathrm{~m}$ & $42.9, \mathrm{CH}^{\mathrm{c}}$ \\
\hline 2 & $5.32 \mathrm{dd}(10.8,7.2)$ & $77.6, \mathrm{CH}$ & $5.43 \mathrm{dd}(10.4,8.0)$ & $77.9, \mathrm{CH}$ \\
\hline 3 & $5.21 \mathrm{~d}(10.8)$ & $119.6, \mathrm{CH}$ & $5.05 \mathrm{~d}(10.4)$ & $120.5, \mathrm{CH}$ \\
\hline 4 & & $142.4, \mathrm{C}$ & & 142.0, C \\
\hline $5 / 5^{\prime}$ & $2.38 \mathrm{~m} ; 2.24 \mathrm{~m}$ & $39.9, \mathrm{CH}_{2}$ & $2.38 \mathrm{br} \mathrm{d}(14.0) ; 2.19 \mathrm{~m}$ & $39.8, \mathrm{CH}_{2}$ \\
\hline $6 / 6^{\prime}$ & $3.11 \mathrm{~m} ; 2.42 \mathrm{~m}$ & $26.6, \mathrm{CH}_{2}$ & $3.07 \mathrm{~m} ; 2.46$ br d (12.4) & $26.6, \mathrm{CH}_{2}$ \\
\hline 7 & $5.74 \mathrm{dd}(8.4,3.6)$ & $147.8, \mathrm{CH}$ & $5.72 \mathrm{dd}(8.8,4.0)$ & $148.1, \mathrm{CH}$ \\
\hline 8 & & $128.7, \mathrm{C}$ & & $128.8, \mathrm{C}$ \\
\hline 9 & $2.75 \mathrm{br} \mathrm{d}(13.2) ; 1.82 \mathrm{~m}$ & $35.2, \mathrm{CH}_{2}$ & 2.71 br d (13.2); 1.87 ddd $(13.2,7.6,7.6)$ & $35.1, \mathrm{CH}_{2}$ \\
\hline 10 & $2.19 \mathrm{~m}$ & $25.0, \mathrm{CH}_{2}$ & $2.18 \mathrm{~m}$ & $25.0, \mathrm{CH}_{2}$ \\
\hline 11 & $4.93 \mathrm{dd}(8.8,7.6)$ & 122.7, $\mathrm{CH}$ & $4.93 \mathrm{dd}(8.4,8.0)$ & $122.8, \mathrm{CH}$ \\
\hline 12 & & $135.5, \mathrm{C}$ & & $135.3, \mathrm{C}$ \\
\hline $13 / 13^{\prime}$ & $2.01 \mathrm{~m} ; 1.67 \mathrm{~m}$ & $36.6, \mathrm{CH}_{2}$ & $2.07 \mathrm{~m} ; 1.69 \mathrm{~m}$ & $36.1, \mathrm{CH}_{2}$ \\
\hline $14 / 14^{\prime}$ & $1.84 \mathrm{~m} ; 1.35 \mathrm{~m}$ & $27.8, \mathrm{CH}_{2}$ & 1.99 ddd $(12.8,6.4,3.2) ; 1.45 \mathrm{~m}$ & $27.0, \mathrm{CH}_{2}$ \\
\hline 15 & $2.33 \mathrm{dq}(12.0,6.8)$ & $38.8, \mathrm{CH}$ & & $138.7, \mathrm{C}$ \\
\hline 16 & & $179.3, \mathrm{C}$ & & $170.6, \mathrm{C}$ \\
\hline $17 \mathrm{a} / \mathrm{b}$ & $1.25 \mathrm{~d}(6.8)$ & $13.6, \mathrm{CH}_{3}$ & $6.28 \mathrm{~d}(3.2) ; 5.54 \mathrm{~d}(3.2)$ & $120.8, \mathrm{CH}_{2}$ \\
\hline 18 & $1.73 \mathrm{~s}$ & $15.0, \mathrm{CH}_{3}$ & $1.73 \mathrm{~s}$ & $15.3, \mathrm{CH}_{3}$ \\
\hline 19 & & $170.7, \mathrm{C}$ & & $171.7, \mathrm{C}$ \\
\hline 20 & $1.52 \mathrm{~s}$ & $16.0, \mathrm{CH}_{3}$ & $1.54 \mathrm{~s}$ & $16.1, \mathrm{CH}_{3}$ \\
\hline
\end{tabular}

${ }^{\mathrm{a} 1} \mathrm{H}$ NMR $\left(400 \mathrm{MHz}, \mathrm{CDCl}_{3}\right),{ }^{\mathrm{b}}{ }^{13} \mathrm{C}$ NMR $\left(100 \mathrm{MHz}, \mathrm{CDCl}_{3}\right),{ }^{\mathrm{c}}$ Multiplicity-edited ${ }^{13} \mathrm{C}$, DEPT, and HSQC spectra.

The $\mathrm{H}_{2}-13 / \mathrm{H}_{2}-14 / \mathrm{H}-1 / \mathrm{H}-2 / \mathrm{H}-3, \mathrm{H}_{2}-5 / \mathrm{H}_{2}-6 / \mathrm{H}-7, \mathrm{H}_{2}-9 / \mathrm{H}_{2}-10 / \mathrm{H}-11$, and $\mathrm{H}-1 / \mathrm{H}-$ $15 / \mathrm{H}_{3}-17$ spin systems identified by ${ }^{1} \mathrm{H}^{-1} \mathrm{H}$ correlation spectroscopy (COSY) (Figure 2) were fit to the regiochemistry of vicinal couplings in $\mathbf{1}$. Based on the aforementioned data and the results of ${ }^{1} \mathrm{H}_{-}{ }^{13} \mathrm{C}$ long-range correlations obtained from heteronuclear multiplebond coherence (HMBC) analysis, the molecular framework of $\mathbf{1}$ was determined (Figure 2). The vinyl methyls at C-4 and C-12 were established from HMBC correlations between $\mathrm{H}_{3}-18 / \mathrm{C}-3, \mathrm{C}-4, \mathrm{C}-5$, and $\mathrm{H}_{3}-20 / \mathrm{C}-11, \mathrm{C}-12, \mathrm{C}-13$, respectively. The carboxyl group at C-8 was established from an HMBC correlation between one of the $\mathrm{C}-9$ methylene protons $\left(\delta_{\mathrm{H}} 1.84\right)$ and the carbonyl carbon of carboxyl group at $\delta_{\mathrm{C}} 170.7(\mathrm{C}-19)$. An ester carbonyl signal at $\delta_{\mathrm{C}} 179.3(\mathrm{C}-16)$ showed a ${ }^{2} J$-coupling with a methine proton at $\delta_{\mathrm{H}} 2.33(\mathrm{H}-15)$; ${ }^{3} \mathrm{~J}$ - couplings with an oxymethine proton at $\delta_{\mathrm{H}} 5.32(\mathrm{H}-2)$, and methyl protons at $\delta_{\mathrm{H}} 1.25$ $\left(\mathrm{H}_{3}-17\right)$ in the HMBC spectrum established the $\alpha$-methyl- $\gamma$-lactone moiety in $\mathbf{1}$.

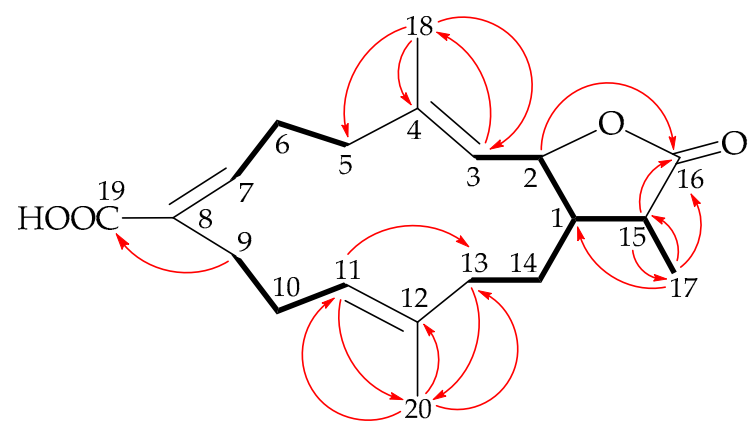

Figure 2. Major COSY $(-)$ and $\operatorname{HMBC}(\frown)$ correlations of $\mathbf{1}$.

The interactions obtained using nuclear Overhauser effect spectroscopy (NOESY) and the data of vicinal ${ }^{1} \mathrm{H}_{-}{ }^{1} \mathrm{H}$ coupling constants revealed the relative stereochemistry of 1 (Figure 3). Biogenetically, in most cases the proton at C-1 is $\beta$-oriented in naturallyoccurring cembranoids from Lobophytum spp. [2]. The NOESY cross-peak of H-1 and H-2 suggested that these two protons were $\beta$-oriented. The vinyl methyl $\mathrm{H}_{3}-18$ exhibited a NOESY response with $\mathrm{H}-2$, but not with $\mathrm{H}-3$, and a NOESY correlation was observed between $\mathrm{H}-3$ 
and $\mathrm{H}-15$, demonstrating the trans configuration of $\Delta^{3}$, and $\mathrm{H}-15$ was therefore $\alpha$-oriented in the $\gamma$-lactone moiety. The trans relationship between $\mathrm{H}-1$ and $\mathrm{H}-15$ was established from a large coupling constant $(J=12.0 \mathrm{~Hz})$ for these two vicinal protons. H-11 showed a NOESY correlation with one of the $\mathrm{C}-13$ methylene protons $\left(\delta_{\mathrm{H}} 2.01\right)$, but not with $\mathrm{H}_{3}-20$, indicating the trans configuration of $\Delta^{11}$. Furthermore, olefin proton H-7 exhibited a NOESY correlation with one of the C-14 methylene protons $\left(\delta_{\mathrm{H}} 1.82\right)$, also demonstrating the cis geometry of $\Delta^{7}$. Based on the aforementioned results, the configurations of the stereogenic centers of 1 were assigned as $\left(1 S^{*}, 2 R^{*}, 15 S^{*}\right)$ (Supplementary Materials, Figures S1-S10).

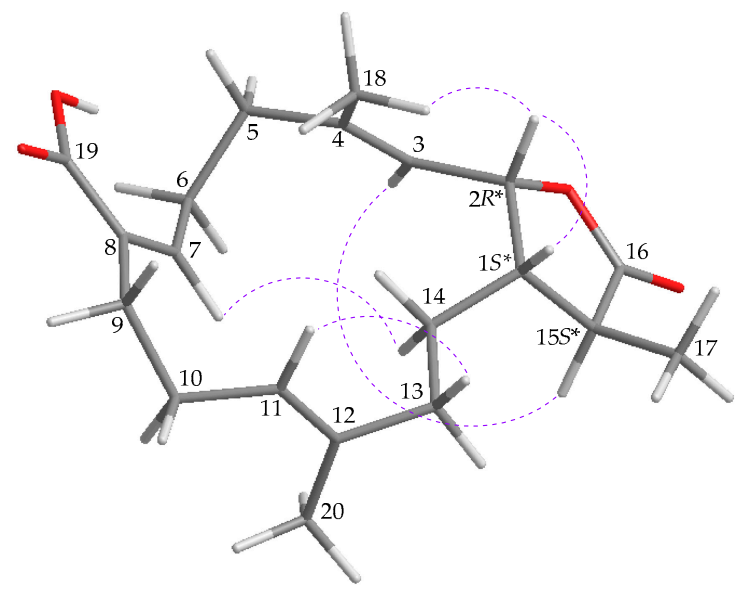

Figure 3. Major protons with NOESY $\left(\because^{\cdots}\right)$ correlations of $\mathbf{1}$.

Single-crystal X-ray diffraction was used to confirm the structure of 1 . The data suggested E-geometries of the C-3/4, C-11/12, and Z-geometry of the C-7/8 carbon-carbon double bonds in 1; in addition, the absolute configurations of the stereogenic carbons of 1 were confirmed as $(1 S, 2 R, 15 S)$ based on an Oak Ridge thermal-ellipsoid plot (ORTEP) of 1 (Figure 4). According to the X-ray determined structure of $\mathbf{1}$, the carboxylic acids formed dimers, in which the monomer units were held together by hydrogen bonds.

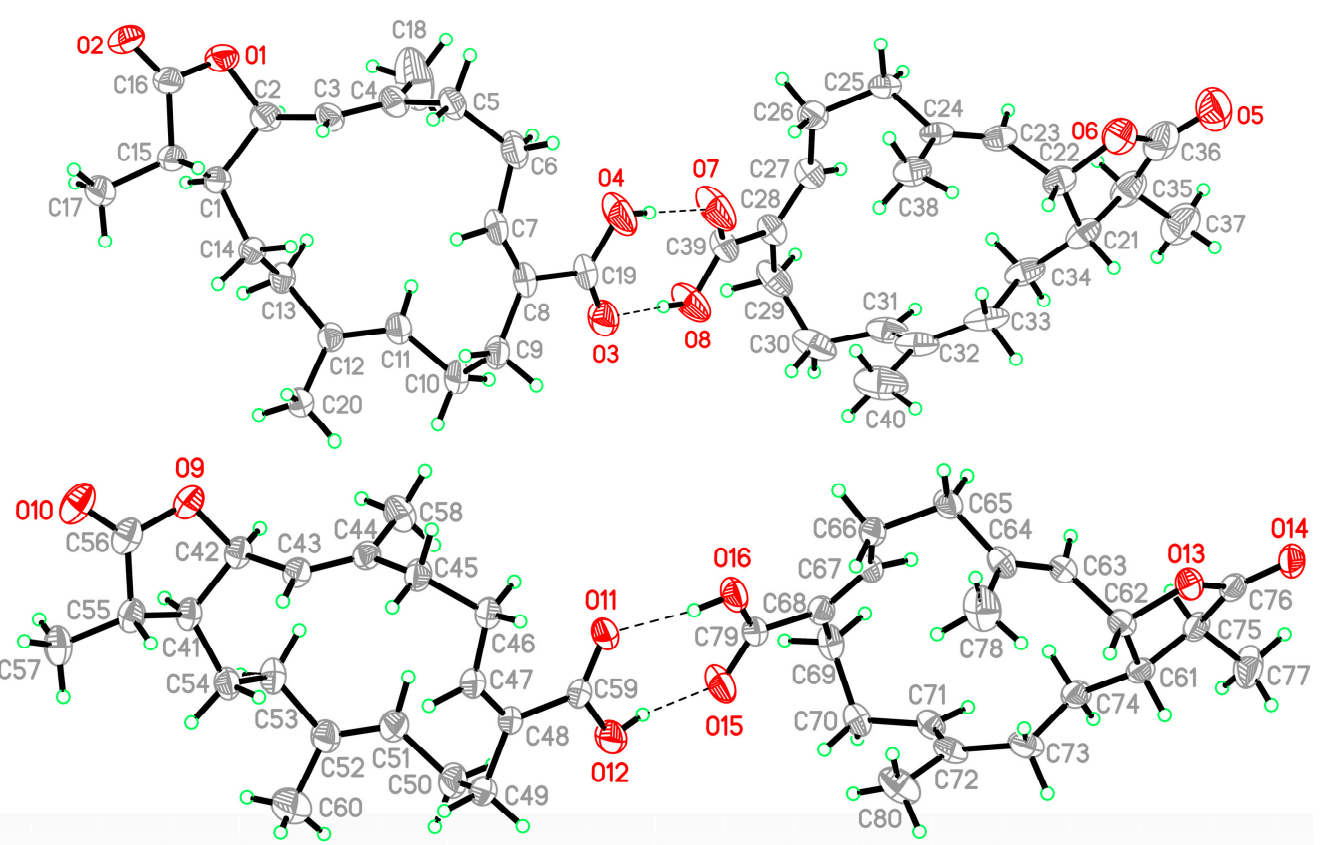

Figure 4. ORTEP plot revealing the absolute configuration of $\mathbf{1}$.

Cembranoid 2 was obtained as colorless prisms, showing a sodiated ESIMS quasimolecular ion peak at $m / z 353$, and was found to have the molecular formula $\mathrm{C}_{20} \mathrm{H}_{26} \mathrm{O}_{4}$ 
by analysis of ${ }^{13} \mathrm{C}$ and ${ }^{1} \mathrm{H}$ NMR data (see Materials and Methods). The result revealed that this compound had 8 degrees of unsaturation. Strong bands at 3665 2398 (broad), 1760 , and $1682 \mathrm{~cm}^{-1}$ in the IR spectrum indicated the presence of $\alpha, \beta$-unsaturated carboxyl and $\gamma$-lactone groups. The ${ }^{13} \mathrm{C}$ NMR and DEPT spectra revealed that 2 had 20 carbons, including two methyls, six $\mathrm{sp}^{3}$ methylenes, one $\mathrm{sp}^{2}$ methylene, two $\mathrm{sp}^{3}$ methines (one bearing a heteroatom), three $\mathrm{sp}^{2}$ methines, and six $\mathrm{sp}^{2}$ non-protonated carbons (one ester carbonyl and one carboxyl group). Therefore, $\mathbf{2}$ was identified as having two rings. It was found that the NMR data of $\mathbf{2}$ were almost identical to those of a known compound, lobohedleolide [3], and these two compounds were found to possess positive optical rotation value, suggesting that compound 2 is lobohedleolide, although the ${ }^{13} \mathrm{C}$ chemical shift for the carboxyl carbon in $2\left(\delta_{C} 171.7, C-19\right)$ was different from that reported $\left(\delta_{C} 173.2\right)$ [3] (Supplementary Materials, Figures S11-S19).

Lobohedleolide (2) was first isolated from octocoral Lobophytum hedleyi, collected from the coral reefs of Yayeyama Islands of Okinawa, Japan [3]. The structure of lobohedleolide was revealed by spectroscopic analysis, and its absolute configuration was concluded from $X$-ray study of its $p$-bromophenacyl ester derivative [3]. In this study, the structure of 2 was determined by single-crystal X-ray diffraction directly for the first time, and the absolute configuration for this compound was elucidated as $(1 S, 2 S)$ (Figure 5). Because the structure of $\mathbf{2}$ has been established by a single-crystal X-ray diffraction analysis, the authors suggested that the ${ }^{13} \mathrm{C}$ chemical shift of carboxyl carbon in structure for lobohedleolide should be re-examined [3].

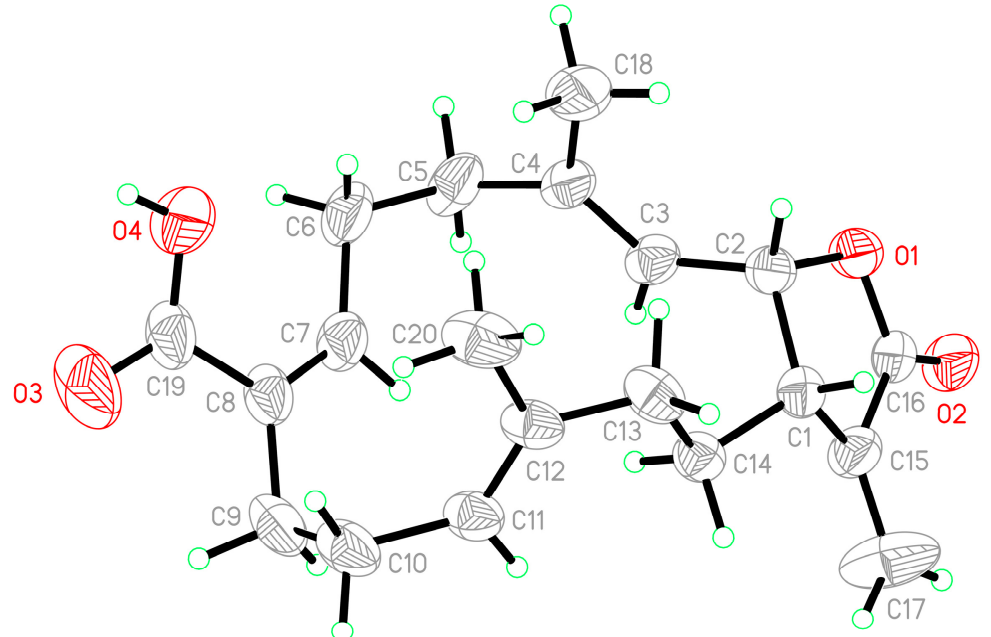

Figure 5. ORTEP plot revealing the absolute configuration of 2 .

The anti-inflammatory effects of lobocrassin I (1) and lobohedleolide (2) were assessed by measuring their effects on proinflammatory proteins/enzymes inducible nitric oxide synthase (iNOS) and cyclooxygenase 2 (COX-2) production from lipopoly-saccharides (LPS)-stimulated RAW264.7 cells (a murine macrophage cell line). Western blotting results showed that cembranoid 2 at $10 \mu \mathrm{m}$ inhibited iNOS expression, which reduced the protein level to $28.50 \%$, as compared with cells in the control group treated with LPS only (Table 2). In previous studies, cembranoid $\mathbf{2}$ was reported to exhibit extensive bioactivities such as cytotoxic [3,5], antiviral [4,16,17], and anti-inflammatory [16,18-20] activities, and the antiinflammatory activity of $\mathbf{2}$ has been evaluated and revealed that $\mathbf{2}$ is effective against both carrageenin induced edema and cotton pellet implantation rat models [18]. Lobocrassin I (1) did not show activity, implying that the exo-methylene substituent at C-15 enhanced the bioactivity in comparison with cembranoid 2 . 
Table 2. Suppression effects of cembranoids 1 and $\mathbf{2}$ on iNOS and COX-2 protein/enzyme expressions in LPS-induced macrophages.

\begin{tabular}{ccccccc}
\hline Compound/Treatment & \multicolumn{2}{c}{ iNOS } & \multicolumn{2}{c}{ COX-2 } & \multicolumn{2}{c}{$\beta$-Actin } \\
\cline { 2 - 6 }$(\mathbf{1 0} \boldsymbol{\mu M})$ & 2.23 & \pm 0.87 & 1.02 & \pm 0.14 & 106.12 & \pm 4.17 \\
Control & 100.01 & \pm 4.27 & 100.00 & \pm 2.62 & 100.00 & \pm 0.74 \\
Vehicle & 90.82 & \pm 2.16 & 110.85 & \pm 2.10 & 102.38 & \pm 2.12 \\
$\mathbf{1}$ & 28.50 & \pm 2.69 & 78.99 & \pm 3.36 & 100.45 & \pm 2.06 \\
$\mathbf{2}$ & 54.53 & \pm 3.58 & 17.66 & \pm 1.75 & 103.14 & \pm 2.46 \\
\hline
\end{tabular}

Values of cells treated with LPS alone were set to $100 \%$ as the reference for normalization. Dexamethasone at $10 \mu \mathrm{m}$ was used as a positive reference to treat cells. Experimental results are shown as the mean \pm S.E.M. The $\beta$-actin of Western blotting is used for loading/internal control.

\section{Materials and Methods}

\subsection{General Experimental Procedures}

A digital polarimeter (model P-1010; JASCO Corp., Tokyo, Japan) was used to determine optical rotations of the samples. IR spectra were collected using a spectro-photometer (model Nicolet iS5 FT-IR; Thermo Fisher Scientific, Waltham, MA, USA). ${ }^{1} \mathrm{H}$ and ${ }^{13} \mathrm{C}$ NMR spectra were recorded on an ECZ-400 spectrometer (Jeol Ltd., Tokyo, Japan) for solutions in $\mathrm{CDCl}_{3}$ (with residual $\mathrm{CHCl}_{3}\left(\delta_{\mathrm{H}} 7.26 \mathrm{ppm}\right)$ and $\mathrm{CDCl}_{3}\left(\delta_{\mathrm{C}} 77.0 \mathrm{ppm}\right)$ as internal standards). For coupling constants $(J)$, the results were given in frequency units, Hz. For ESIMS and HRESIMS, the results were obtained using a SolariX FTMS mass spectrometer (7 Tesla; Bruker, Bremen, Germany). The extracted samples were separated by column chromatography with silica gel (range, 230 to 400 mesh; Merck, Darmstadt, Germany). The purity of a compound can be determined by Thin-layer chromatography (TLC), a method for analyzing mixtures by separating the compounds in the mixture. The TLC plates with silica gel coated with fluorescent indicator $\mathrm{F}_{254}$ were employed. For visualization, the plates were charred with $10 \%(v / v)$ aqueous sulfuric acid solution, then heated at $105^{\circ} \mathrm{C}$ until spots were seen. For normal-phase HPLC separation, a system containing a pump (Hitachi model L-7110; Tokyo, Japan) and an injection interface (No. 7725; Rheodyne) was employed, which was equipped with a semi-prep column with a dimension of $2 \times 25 \mathrm{~cm}$, $5 \mu \mathrm{m}$ particle size (Sigma, St. Louis, MO, USA). For reverse-phase HPLC separation, a system composed of a pump (Hitachi model L-2130, Tokyo, Japan) and a diode-array detector (LaChrom L-2455, Hitachi, Tokyo, Japan) were used, which was equipped with a column with a dimension of $2.1 \times 25 \mathrm{~cm}, 5 \mu \mathrm{m}$ particle size (Phenomenex, Torrance, CA, USA).

\subsection{Soft Coral Specimens}

The soft coral L. crassum was manually collected by an underwater diver with a breathing apparatus from the marine habitat around Southern Taiwan on 23 July 2020. The specimens were frozen directly after harvesting. Identification of the specimens was performed by one of the authors of this study (Y.-T.Y.) by assessment of the features and comparison with the characteristics reported in the literature [7,8]. A representative sample of the soft coral (voucher no.: NMMBA-TW-SC-2020-0723) was stored in the National Museum of Marine Biology and Aquarium, Taiwan.

\subsection{Cembranoid Compound Preparation}

Lobophytum crassum (wet/dry weight $=1174 \mathrm{~g} / 591 \mathrm{~g}$ ) was crushed and then extracted with a mixture of $\mathrm{MeOH}$ and $\mathrm{CH}_{2} \mathrm{Cl}_{2}$ (1:1) to give an extract (22.4 g), that was next separated by solvent-partition with EtOAc and $\mathrm{H}_{2} \mathrm{O}$. The EtOAc extract (7.34 g) was then placed in an $\mathrm{SiO}_{2}$ column and washed with an eluent of hexanes/EtOAc (by stepwise-gradient increase from 100:1—pure EtOAc) to yield 12 fractions A-L. Fraction J (294 mg) was then purified by semi-prep normal-phase HPLC to give eight fractions J1-J8. Fraction J3 $(161.0 \mathrm{mg})$ was then purified by semi-prep reverse-phase HPLC $\left(\mathrm{MeOH}: \mathrm{H}_{2} \mathrm{O}=65: 35(v / v)\right.$; at a rate of $5.0 \mathrm{~mL} / \mathrm{min})$ to afford compounds $2(47.1 \mathrm{mg})$ and $\mathbf{1}(16.6 \mathrm{mg})$. 
Lobocrassin I (1): Colorless prisms; $[\alpha]_{\mathrm{D}}^{22}+46$ (c 0.03, $\left.\mathrm{CHCl}_{3}\right)$; IR (ATR) $v_{\max } 3749 \sim 2216$ (broad), 1766, $1710 \mathrm{~cm}^{-1} ;{ }^{1} \mathrm{H}$ NMR (400 MHz, CDCl $\mathrm{Mn}_{3}$ ) ${ }^{13} \mathrm{C} \mathrm{NMR}\left(100 \mathrm{MHz}, \mathrm{CDCl}_{3}\right)$ data, see Table 1; ESIMS: $m / z 355$ [M + Na] ${ }^{+}$; HRESIMS: $m / z 355.18815$ (calcd. for $\mathrm{C}_{20} \mathrm{H}_{28} \mathrm{O}_{4}$ $+\mathrm{Na}, 355.18798$ ).

Lobohedleolide (2): Colorless prisms; $[\alpha]_{\mathrm{D}}^{22}+48\left(c 0.21, \mathrm{CHCl}_{3}\right)$ (ref. [3] $[\alpha]_{\mathrm{D}}+104.2$ (c 1.12, $\left.\mathrm{CHCl}_{3}\right)$; ref. [4] $[\alpha]_{\mathrm{D}}+97.3\left(\right.$ c $\left.0.38, \mathrm{CHCl}_{3}\right)$ ); IR (ATR) $v_{\max }$ 3665 2398 (broad), 1760, $1682 \mathrm{~cm}^{-1} ;{ }^{1} \mathrm{H}$ NMR $\left(400 \mathrm{MHz}, \mathrm{CDCl}_{3}\right)$ and ${ }^{13} \mathrm{C} \mathrm{NMR}\left(100 \mathrm{MHz}, \mathrm{CDCl}_{3}\right)$ data, see Table 1; ESIMS: $m / z 353[\mathrm{M}+\mathrm{Na}]^{+}$.

\subsection{Single-Crystal X-ray Crystallography of Lobocrassin I (1)}

Suitable colorless prisms of 1 were acquired from EtOA/acetone (4:1). The crystal $\left(0.256 \times 0.210 \times 0.210 \mathrm{~mm}^{3}\right)$ belongs to the monoclinic system, space group $P 2_{1}$ (\#4), with $a=19.0021(4) \AA, b=9.3796(2) \AA, c=22.1329(5) \AA, V=3810.26(14) \AA^{3}, Z=8$, $D_{\text {calcd }}=1.159 \mathrm{Mg} / \mathrm{m}^{3}$, and $\lambda(\mathrm{Mo} \mathrm{K} \alpha)=0.71073 \AA$. Intensity data (up to $\theta_{\max }$ of $27.5^{\circ}$ ) were obtained using an X-ray diffractometer (Bruker D8 Venture, Bremen, Germany). All 30,010 reflections were collected. By using direct methods and a full-matrix least-squares refinement [21,22], the structure of compound 1 was obtained. The refined structural model converged to a final R1 $=0.0546$ and $\mathrm{wR} 2=0.1277$ for 17,444 observed reflections, with $I>2 \sigma(I)$ and 881 variable parameters. The absolute configuration of this molecule was confirmed by an absolute structure Flack parameter, $x=0.0(4)[23,24]$. Crystallographic data of compound 1 have been deposited with the Cambridge Crystallographic Data Center (CCDC) as supplementary publication no. CCDC 2053256 [25].

\subsection{Single-Crystal X-ray Crystallography of Lobohedleolide (2)}

Suitable colorless prisms of 2 were acquired from MeOH. The crystal $(0.324 \times 0.193 \times$ $0.152 \mathrm{~mm}^{3}$ ) belongs to the orthorhombic system, space group $P 2{ }_{1}{ }_{2} 2_{1}$ (\#19), with $a=8.8283(4)$ $\AA, b=12.4788(6) \AA, c=16.8460(7) \AA, V=1855.87(14) \AA^{3}, Z=4, D_{\text {calcd }}=1.183 \mathrm{Mg} / \mathrm{m}^{3}$, and $\lambda(\mathrm{Mo} \mathrm{K} \alpha)=0.71073 \AA$. Intensity data (up to $\theta_{\max }$ of $30.0^{\circ}$ ) were obtained using an X-ray diffractometer (Bruker D8 Venture, Bremen, Germany). All 12,446 reflections were collected. The structure of compound 2 was obtained using the same processes as described above for compound 1. The refined structural model converged to a final $\mathrm{R} 1=0.0502$ and $\mathrm{wR} 2=0.1294$ for 5399 observed reflections, with $I>2 \sigma(I)$ and 220 variable parameters. The absolute configuration of this molecule was confirmed by Flack parameter $x=-0.1(5)[23,24]$. Crystallographic data for the structure of lobohedleolide (2) were also deposited with the CCDC as supplementary publication no. CCDC 2043446 [25].

\subsection{In Vitro Anti-inflammatory Assay}

Murine RAW 264.7 macrophages were obtained from the American Type Culture Collection (ATCC; No. TIB-71). Inflammation in macrophages was induced by incubating them for $16 \mathrm{~h}$ in a medium containing only LPS $(0.01 \mu \mathrm{g} / \mathrm{mL})$ without compounds. For the anti-inflammatory activity assay, compounds $(10 \mu \mathrm{m})$ were added to the cells 5 min before LPS challenge. The cells were then washed with ice cold phosphate-buffered saline (PBS), lysed in ice-cold lysis buffer (50 mM Tris, pH 7.5, $150 \mathrm{mM} \mathrm{NaCl}, 1 \%$ Triton X-100, $100 \mu \mathrm{g} / \mathrm{mL}$ phenylmethylsulfonyl fluoride, $1 \mu \mathrm{g} / \mathrm{mL}$ aprotinin), and then centrifuged at 20,000 $\times g$ for 30 min at $4{ }^{\circ} \mathrm{C}$. The supernatant was decanted from the pellet and retained for Western blot analysis of pro-inflammation inducible nitric oxide synthase (iNOS) and cyclooxygenase-2 (COX-2) protein expression. Protein concentrations were determined using the detergent compatible (DC) protein assay kit (Bio-Rad, Hercules, CA, USA). Western blotting was performed according to the method described in a previous study [26]. An equal volume of sample buffer (2\% 2-mercaptoethanol, 2\% sodium dodecyl sulfate (SDS), $0.1 \%$ bromophenol blue, $10 \%$ glycerol, and $50 \mathrm{mM}$ Tris- $\mathrm{HCl}$ ( $\mathrm{pH} 7.2)$ ) was added to the samples, and the protein lysates were loaded onto a 10\% SDS- polyacrylamide gel. Electrophoresis was carried out at $150 \mathrm{~V}$ for $90 \mathrm{~min}$. After electro-phoresis, gels were transferred overnight at $4{ }^{\circ} \mathrm{C}$ in transfer buffer (380 mM glycine, $50 \mathrm{mM}$ Tris- $\mathrm{HCl}, 1 \%$ SDS and 20\% methanol) onto 
a polyvinylidene difluoride membrane (PVDF; Immobilon-P, Millipore Corp., Billerica, MA, USA ( $0.45 \mu \mathrm{m}$ pore size)). The PVDF membrane was first blocked with $5 \%$ non-fat dry milk in Tris-buffered saline containing $0.1 \%$ Tween (TTBS; $20 \mathrm{mM}$ Tris- $\mathrm{HCl}, 0.1 \%$ Tween 20, and $137 \mathrm{mM} \mathrm{NaCl}(\mathrm{pH} 7.4)$ ) and incubated overnight at $4{ }^{\circ} \mathrm{C}$ with the primary antibodies for iNOS, COX-2, and $\beta$-actin proteins. Anti-iNOS and anti-COX-2 antibodies were purchased from Cayman Chemical Company (Ann Arbor, MI, USA). A horseradish peroxidase-conjugated secondary antibody was used for detection. It was obtained from Jackson ImmunoResearch Laboratories (West Grove, PA, USA). The bound antibodies were detected by chemiluminescence (Millipore Corp.). The images were obtained using the UVP BioChemi Imaging System, and the LabWorks 4.0 software (UVP, Upland, CA, USA) was used to quantify the relative densities.

\section{Conclusions}

A series of cembranoids, including lobocrassins A-F [27-29], have been obtained from this target organism. The structures of a new compound lobocrassin I (1) and its analogue lobohedleolide (2), two cembranoids isolated from L. crassum containing $\alpha, \beta$-unsaturated carboxyl group and $\gamma$-lactone systems, were elucidated using spectroscopic methods and $\mathrm{X}$-ray analysis. Cembranoid 2 exhibited effective inhibition of iNOS production. Structureactivity relationship (SAR) comparison also indicated that the exomethylene group at C-15 has an important role in the activity against the inflammatory response. We have started to optimize the aquaculture conditions for this octocoral in tanks, with the aim of culturing a large quantity of coral that is able to provide a stable supply of bioactive materials. This approach will protect the coral population in natural marine habitats from over-exploitation [30,31], and provide raw materials of consistent quality.

Supplementary Materials: Supplementary materials are available online at https://www.mdpi. com/1660-3397/19/3/130/s1. ESIMS, IR, 1D $\left({ }^{1} \mathrm{H}\right.$ and $\left.{ }^{13} \mathrm{C}\right)$ and 2D (HSQC, HMBC, COSY, and NOESY) NMR spectra of lobocrassin I (1) Figures S1-S10 and lobohedleolide (2) Figures S10-S19. HRESIMS spectra of lobocrassin I (1).

Author Contributions: Conceptualization, M.-K.Y. and P.-J.S.; investigation, Y.-T.Y., S.-C.L., G.-H.L., Z.-H.W., T.-L.H., Y.-J.W., J.-J.C., and L.-S.F.; writing—original draft preparation, Y.-T.Y. and P.-J.S.; writing - review and editing, Y.-T.Y., S.-C.L., M.-K.Y., and P.-J.S. All authors have read and agreed to the published version of the manuscript.

Funding: The research was funded by grants from the National Museum of Marine Biology and Aquarium; the National Dong Hwa University; An Nan Hospital, China Medical University, Tainan, Taiwan (ANHRF109-18); and the Ministry of Science and Technology (MOST 107-2320-B-291-001MY3, 109-2320-B-291-001-MY3, and 109-2320-B-276-002-MY3), Taiwan, awarded to Yu-Jen Wu and Ping-Jyun Sung. All funding is gratefully acknowledged.

Institutional Review Board Statement: Not applicable.

Informed Consent Statement: Not applicable.

Acknowledgments: The authors are thankful to Hsiao-Ching Yu and Chao-Lien Ho, the High Valued Instrument Center, National Sun Yat-sen University for the mass (MS000600) and NMR (NMR001100) spectra (MOST 110-2731-M-110-001); and to the Instrumentation Center, National Taiwan University for providing $\mathrm{X}$-ray facilities.

Conflicts of Interest: The authors declare no conflict of interest.

\section{References}

1. Yang, B.; Zhou, X.-F.; Lin, X.-P.; Liu, J.; Peng, Y.; Yang, X.-W.; Liu, Y. Cembrane diterpenes chemistry and biological properties. Curr. Org. Chem. 2012, 16, 1512-1539. [CrossRef]

2. Rodrigues, I.G.; Miguel, M.G.; Mnif, W. A brief review on new naturally occurring cembranoid diterpene derivatives from the soft corals of the genera Sarcophyton, Sinularia, and Lobophytum since 2016. Molecules 2019, 24, 781. [CrossRef] [PubMed]

3. Uchio, Y.; Toyota, J.; Nozaki, H.; Nakayama, M.; Nishizono, Y.; Hase, T. Lobohedleolide and (7Z)-lobohedleolide, new cembranolides from the soft coral Lobophytum hedleyi Whitelegge. Tetrahedron Lett. 1981, 22, 4089-4092. [CrossRef] 
4. Rashid, M.A.; Gustafson, K.R.; Boyd, M.R. HIV-Inhibitory cembrane derivatives from a Philippines collection of the soft coral Lobophytum species. J. Nat. Prod. 2000, 63, 531-533. [CrossRef]

5. Duh, C.-Y.; Wang, S.-K.; Huang, B.-T.; Dai, C.-F. Cytotoxic cembrenolide diterpenes from the Formosan soft coral Lobophytum crassum. J. Nat. Prod. 2000, 63, 884-885. [CrossRef]

6. Lü, F.; Chi, K.-Y.; Dai, R.-J.; Deng, Y.-L. Isolation and structural identification of chemical constituents from Sinularia sp. Trans. Beijing Inst. Technol. 2012, 32, 1096-1100.

7. Benayahu, Y.; Jeng, M.-S.; Perkol-Finkel, S.; Dai, C.-F. Soft corals (Octocorallia: Alcyonacea) from Southern Taiwan: II. Species diversity and distributional patterns. Zool. Stud. 2004, 43, 548-560.

8. Dai, C.-F.; Chin, C.-H. Octocoral Fauna of Kenting National Park, 1st ed.; Kenting National Park Headquaters: Kenting Pingtung, Taiwan, 2019; pp. 126-127.

9. Chao, C.-H.; Wen, Z.-H.; Wu, Y.-C.; Yeh, H.-C.; Sheu, J.-H. Cytotoxic and anti-inflammatory cembranoids from the soft coral Lobophytum crassum. J. Nat. Prod. 2008, 71, 1819-1824. [CrossRef] [PubMed]

10. Wanzola, M.; Furuta, T.; Kohno, Y.; Fukumitsu, S.; Yasukochi, S.; Watari, K.; Tanaka, C.; Higuchi, R.; Miyamoto, T. Four new cembrane diterpenes isolated from an Okinawan soft coral Lobophytum crassum with inhibitory effects on nitric oxide production. Chem. Pharm. Bull. 2010, 58, 1203-1209. [CrossRef]

11. Cuong, N.X.; Thao, N.P.; Luyen, B.T.T.; Ngan, N.T.T.; Thuy, D.T.T.; Song, S.B.; Nam, N.H.; Kiem, P.V.; Kim, Y.H.; Minh, C.V. Cembranoid diterpenes from the soft coral Lobophytum crassum and their anti-inflammatory activities. Chem. Pharm. Bull. 2014, 62, 203-208. [CrossRef]

12. Thao, N.P.; Luyen, B.T.T.; Ngan, N.T.T.; Song, S.B.; Cuong, N.X.; Nam, N.H.; Kiem, P.V.; Kim, Y.H.; Minh, C.V. New antiinflammatory cembranoid diterpenoids from the Vietnamese soft coral Lobophytum crassum. Bioorg. Med. Chem. Lett. 2014, 24, 228-232. [CrossRef]

13. Zhao, M.; Cheng, S.; Yuan, W.; Xi, Y.; Li, X.; Dong, J.; Huang, K.; Gustafson, K.R.; Yan, P. Cembranoids from a Chinese collection of the soft coral Lobophytum crassum. Mar. Drugs 2016, 14, 111. [CrossRef]

14. Mohamed, T.A.; Elshamy, A.I.; Hussien, T.A.; Su, J.-H.; Sheu, J.-H.; Hegazy, M.E.F. Lobophylins F-H: Three new cembrene diterpenoids from soft coral Lobophytum crassum. J. Asian Nat. Prod. Res. 2017, 19, 201-207. [CrossRef]

15. Lai, K.-H.; You, W.-J.; Lin, C.-C.; El-Shazly, M.; Liao, Z.-J.; Su, J.-H. Anti-inflammatory cembranoids from the soft coral Lobophytum crassum. Mar. Drugs 2017, 15, 327. [CrossRef]

16. Lin, C.-K.; Tseng, C.-K.; Liaw, C.-C.; Huang, C.-Y.; Wei, C.-K.; Sheu, J.-H.; Lee, J.-C. Lobohedleolide suppresses hepatitis C virus replication via JNK/c-Jun-C/EBP-mediated downregulation of cyclooxygenase-2 expression. Sci. Rep. 2018, 8, 8676. [CrossRef]

17. Gustafson, K.R.; Oku, N.; Milanowski, D.J. Antiviral marine natural products: The structure of lobohedleolide shown as compound 8 in this review article should be revised. Curr. Med. Chem. Anti Infec. Agents 2004, 3, 233-249. [CrossRef]

18. Radhika, P.; Rao, P.R.; Archana, J.; Rao, N.K. Anti-inflammatory activity of a new sphingosine derivative and cembrenoid diterpene (lobohedleolide) isolated from marine soft corals of Sinularia crassa Tixier-Durivault and Lobophytum species of the Andaman and Nicobar Islands. Biol. Pharm. Bull. 2005, 28, 1311-1313. [CrossRef]

19. Oda, T.; Wewengkang, W.; Kapojos, M.M.; Mangindaan, R.P.; Lee, J.-S.; Namikoshi, M. Lobohedleolide induces interleukin-8 production in LPS-stimulated human monocytic cell line THP-1. Int. J. Appl. Res. Nat. Prod. 2011, 4, 16-21.

20. González, Y.; Torres-Mendoza, D.; Jones, G.E.; Fernandez, P.L. Marine diterpenoids as potential anti-inflammatory agents. Mediat. Inflamm. 2015, 63543. [CrossRef]

21. Sheldrick, G.M. SHELXT-Integrated space-group and crystal-structure determination. Acta Crystallogr. 2015, A71, 3-8. [CrossRef]

22. Sheldrick, G.M. Crystal structure refinement with SHELXL. Acta Crystallogr. 2015, C71, 3-8.

23. Flack, H.D. On enantiomorph-polarity estimation. Acta Crystallogr. 1983, A39, 876-881. [CrossRef]

24. Flack, H.D.; Bernardinelli, G. Absolute structure and absolute configuration. Acta Crystallogr. 1999, A55, 908-915. [CrossRef]

25. CCDC Homepage. Available online: http://www.ccdc.cam.ac.uk/conts/retrieving.html (accessed on 31 December 2020).

26. Chen, C.-H.; Chen, N.-F.; Feng, C.-W.; Cheng, S.-Y.; Hung, H.-C.; Tsui, K.-H.; Hsu, C.-H.; Sung, P.-J.; Chen, W.-F.; Wen, Z.-H. A coral-derived compound improves functional recovery after spinal cord injury through its antiapoptotic and anti-inflammatory effects. Mar. Drugs 2016, 14, 160. [CrossRef]

27. Kao, C.-Y.; Su, J.-H.; Lu, M.-C.; Hwang, T.-L.; Wang, W.-H.; Chen, J.-J.; Sheu, J.-H.; Kuo, Y.-H.; Weng, C.-F.; Fang, L.-S.; et al. Lobocrassins A-E: New cembrane-type diterpenoids from the soft coral Lobophytum crassum. Mar. Drugs 2011, 9, $1319-1331$. [CrossRef]

28. Lee, C.-H.; Kao, C.-Y.; Kao, S.-Y.; Chang, C.-H.; Su, J.-H.; Hwang, T.-L.; Kuo, Y.-H.; Wen, Z.-H.; Sung, P.-J. Terpenoids from the octocorals Menella sp. (Plexauridae) and Lobophytum crassum (Alcyonacea). Mar. Drugs 2012, 10, 427-438. [CrossRef]

29. Yin, F.-Z.; Huan, X.-J.; Mudianta, I.W.; Miao, Z.-H.; Wang, H.; Guo, Y.-W.; Li, X.-W. Polyoxygenated cembranoids from soft coral Lobophytum crassum and their anti-tumoral activity. Chin. J. Chem. 2021, 39, 640-646. [CrossRef]

30. Yan, H.-Y. Harvesting drugs from the seas and how Taiwan could contribute to this effort. Chang. J. Med. 2004, 9, 1-6.

31. Leal, M.C.; Calado, R.; Sheridan, C.; Alimonti, A.; Osinga, R. Coral aquaculture to support drug discovery. Trends Biotechnol. 2013, 31, 555-561. [CrossRef] [PubMed] 